\title{
VALIDASI METODE ANALISIS PIPERIN DALAM LADA HITAM SECARA SPEKTROFOTOMETRI
}

\author{
Validation Of Piperin Analyzing Method By Spectrofotometry
}

\author{
Shintawati ${ }^{1)}$, Oktaf Rina ${ }^{2)}$, Iskandar Zulkarnain ${ }^{3)}$ \\ ${ }^{1), 2), 3)}$ Politeknik Negeri Lampung, Jalan Soekarno Hatta No 10, Bandar Lampung-35144, Indonesia \\ Email : shintawatisatria@gmail.com
}

\begin{abstract}
ABSTRAK. Lada hitam asal Provinsi Lampung dikenal sejak zaman penjajahan Belanda karena kepedasannya. Zat aktif pemberi rasa pedas tersebut adalah piperin. Salah satu metoda analisa piperin adalah menggunakan spektrofotometri UV Vis. Upaya modifikasi terhadap metode analisa standar dilaksanakan dengan mengefektifkan jumlah penggunaan bahan kimia namun tetap menghasilkan data pengujian yang valid dan tak terbantahkan. Penelitian ini bertujuan untuk memvalidasi metode pengujian piperin yang dimodifikasi dari metoda standar melalui penilaian parameter presisi, akurasi, linieritas, serta penetapan nilai LOD dan LOQ. Hasil penelitian menunjukkan seluruh parameter validasi memenuhi persyaratan keberterimaan validasi. Diperoleh nilai simpangan baku relatif (\%RSD) sebesar 0,10123 dengan nilai CV Horwitz 3.05145, nilai perolehan kembali 98,88-101,87\% dan koefisien determinasi kurva linieritas sebesar 0,999. Nilai LOD dan LOQ masing-masing sebesar 0,002116 dan 0,007054 ppm
\end{abstract}

Kata Kunci : lada hitam, piperin dan validasi.

\begin{abstract}
ABSTRAC. Black pepper from Lampung Province is known since the Dutch colonial era because of its spiciness. The spicy flavor active substance is piperine. One method of piperine analysis is using UV Vis spectrophotometer. Modification efforts on standard analysis methods are carried out by streamlining the amount of chemical use but still producing valid and undisputable test data. This study aims to validate the modified piperine testing methods from standard methods through the assessment of parameters of precision, accuracy, linearity, and determination of $L O D$ and $L O Q$ values. The results of the study show that all parameters meet the requirements for accepting validation. Obtained relative standard deviation value (\% RSD) is 0.10123 with the value of CV Horwitz 3.05145, recovery value 98.88-101.87\% and the coefficient of determination of the linearity curve 0.999. The LOD and LOQ values are 0.002116 and 0.007054 ppm, respectively.
\end{abstract}

Key words : black pepper, pipperin and validation.

\section{PENDAHULUAN}

Lada Hitam merupakan salah satu komoditi ekspor unggulan Provinsi Lampung, dengan volume ekspor 13.922 ton pada tahun 2017 (Lampung Directory, Dinas Perdagangan Provinsi Lampung, 2018). Lada hitam asal Provinsi Lampung terkenal dengan kepedasannya yang dicirikan oleh parameter piperin. Kadar piperin dalam lada hitam bervariasi 2-7,4\% (Leila Gorgani, 2017). Analisa kadar piperin dapat menggunakan Spektrofotometer UV Vis, HPLC, dan GC. Pengujian piperin menggunakan spektrofotometer relatif lebih murah dengan selektifitas yang tinggi. Salah satu metode standar untuk analisis kadar piperin dalam lada hitam adalah SNI 005 : 2013 Lada Hitam. Prinsip analisis piperin dalam SNI 005:2013 adalah ekstraksi termal dengan pelarut etanol pro analisis (pa) dilanjutkan dengan pembacaan absorbansi menggunakan spektrofotometer UV Vis pada panjang gelombang $343 \mathrm{~nm}$. Menurut Gupta Vishvnath, 2011, piperin memiliki serapan maksimum pada panjang gelombang $342,5 \mathrm{~nm}$ dalam pelarut metanol. Selain sifat kimia yang dimiliki senyawa, spektrum absorbansi juga dipengaruhi oleh pelarut (Underwood, 1988). Menurut Nerdy, 2017, asam mefenamat yang memiliki serapan maksimum pada panjang gelombang $279 \mathrm{~nm}$ sampai $350 \mathrm{~nm}$ dapat ditetapkan kadarnya menggunakan spektrofotometer ultraviolet. Berdasarkan 
literatur tersebut maka piperin memiliki serapan maksimum pada daerah ultraviolet, sehingga pengukuan piperin dapat menggunakan spektrofotometer UV VIS.

Dalam metoda ini setelah ekstraksi termal, dilakukan 3 (tiga) tahap pengenceran. Pengenceran pertama dilakukan dengan menambahkan larutan hasil ekstraksi termal hingga volume $100 \mathrm{ml}$. Pengenceran pertama ini menggunakan $\pm 50 \mathrm{ml}$ pelarut yaitu etanol pa. Pengenceran kedua dilakukan dengan memipet 5 $\mathrm{ml}$ larutan hasil pengenceran pertama dan menepatkannya hingga volume $50 \mathrm{ml}$. Pengenceran ketiga dilakukan dengan memipet 5 $\mathrm{ml}$ larutan hasil pengenceran kedua kedalam labu takar $25 \mathrm{ml}$ dan ditepatkan hingga tanda tera. Pengenceran tahap ketiga membutuhkan $\pm 20 \mathrm{ml}$ pelarut yaitu etanol pa. Jika digabungkan tahap 2 dan tahap 3 pengenceran yang dilakukan 50 kali dengan jumlah pemakaian pelarut $\pm 60 \mathrm{ml}$.

Penelitian ini memodifikasi cara pengenceran pada tahap kedua dan ketiga. Setelah pengenceran tahap pertama, $0,5 \mathrm{ml}$ sampel hasil pengenceran tahap pertama ditempatkan dalam labu ukur $25 \mathrm{ml}$ lalu ditepatkan dengan etanol pa hingga tanda tera, sehingga tetap melakukan pengenceran 50 kali, namun jumlah bahan kimia yang digunakan \pm 20 ml.ISO 17025:2017 mensyaratkan untuk metode analisis yang dimodifikasi dari metode standar, laboratorium wajib melakukan validasi metode pengujian. Validasi adalah konfimasi melalui pengujian dan pengadaan bukti yang objektif bahwa persyaratan tertentu untuk suatu maksud khusus dipenuhi (Anwar Hadi, 2017). Menurut AOAC dalam How to Meet ISO 17025 Requirements for Method Verification, 2008, parameter validasi metode pengujian antara lain presisi, akurasi, linieritas, selektifitas, batas deteksi (LOD), batas kuantitatasi (LOQ). Pemilihan parameter yang diuji tergantung pada jenis dan metode analisis yang akan divalidasi.

Akurasi merupakan ukuran yang menunjukkan kedekatan hasil uji dengan nilai sebenarnya. Akurasi dapat diketahui dengan melakukan uji perolehan kembali (recovery) dengan menambahkan bahan standar yang telah diketahui nilai benarnya. Presisi merupakan pengukuran kesalahan acak, yaitu kesalahan yang terjadi secara kebetulan dan sulit untuk dihindari misalnya faktor keterampilan analis, kondisi analis, fluktuasi listrik dan lain-lain (Riyanto,
2014). Uji presisi dapat dilakukan dengan uji repeatabilitas dimana pengujian dilakukan berulang dengan peralatan, personil dan kondisi yang sama dan serta reproducibility, yaitu pengujian berulang dengan kondisi yang berbeda, misal alat, analis dan waktu yang berbeda. Linieritas merupakan rasio kenaikan respon pengujian untuk setiap kenaikan konsentrasi analit. Evaluasi nilai linieritas dilakukan dengan menghitung nilai koefisien determinasidari kurva linieritas. Batas deteksi (LOD) merupakan jumlah terkecil dari analit yang dapat dideteksi sedangkan batas kuantitasi (LOQ) merupakan konsentrasi terendah dari analit yang dapat diterima dan dapat dipertanggungjawabkan secara kuantitatif (Nining Sugihartini, 2014). Tujuan dari penelitian ini adalah memvalidasi metode analisa piperin SNI 005:2013 yang dimodifikasi.

\section{METODE PENELITIAN}

Bahan yang digunakan antara lain kertas lada hitam, aluminium foil, etanol pa, dan piperin murni $99 \%$ merk Aldrin. Alat yang dipakai dalam pengujian adalah penggiling biji lada, saringan 2 $\mu \mathrm{m}$, neraca analitik, gelas kimia, heating mantel, kondensor, labu takar, corong, kertas saring Whatman $0,45 \mu \mathrm{m}$, spektrofotometer UV VIS (Jenway).

\section{Uji Presisi}

Sampel lada hitam yang telah digiling sebanyak $\pm 0,5$ gram diekstraksi menggunakan pelarut etanol pa secara termal selama 3 jam. Hasil ekstraksi disaring kedalam labu takar 100 $\mathrm{ml}$ lalu ditepatkan menggunakan etanol pa hingga tanda tera. Larutan tersebut sebanyak 0,5 ml diencerkan dalam labu $25 \mathrm{ml}$ kemudian dicek absorbansinya menggunakan spektrofotometer UV Vis pada panjang gelombang $343 \mathrm{~nm}$. Kadar piperin dihitung menggunakan rumus :

$$
\frac{\mathrm{A}}{\mathrm{A}_{1} \mathrm{~cm}^{1 \%}} \times \frac{25}{0,5} \times \frac{100}{M} \times \frac{100}{100-K a}
$$

$\mathrm{A}=$ absorbansi terukur

$\mathrm{M}=$ berat sampel lada hitam $(\mathrm{g})$

$\mathrm{Ka}=$ Kadar air (\%)

$\mathrm{A}_{1} \mathrm{~cm}^{1 \%}=$ absorbansi pada $343 \mathrm{~nm}$ dari $1 \%$

larutan piperin dan cel $1 \mathrm{~cm}$ yaitu 1238 .

Pengujian presisi dilaksanakan melalui pengulangan sebanyak 7 kali terhadap sampel 
yang sama. Evaluasi uji presisi dilakukan dengan menghitung RSD dan nilai CV Horwitz (Riyanto, 2014).

$$
\begin{aligned}
& \text { RSD }=\frac{\text { Simpangan Baku }}{\text { Rata }- \text { rata }} \ldots \ldots . . . \\
& \text { CV hitung }=\text { RSD X } 100 \% \ldots \\
& \text { CV Horwitz }(\%)=2^{(1-0,5 \log C)} \\
& \text { C }=\text { konsentrasi analit }
\end{aligned}
$$

Keberterimaan nilai RSD untuk senyawasenyawa aktif menurut Ridho Asra, 2017 dan Riyanto, 2014, adalah kurang dari $2 \%$. Nilai CV Horwitz dibandingkan dengan $\mathrm{CV}$ hitung , repeatabilitas dapat diterima jika $\mathrm{CV}$ hitung lebih kecil atau sama dengan 2/3 CV Horwitz (Ambarwati, 2013).

\section{Uji Akurasi.}

Uji akurasi dilaksanakan dengan menambahkan piperin murni ke dalam sampel. Timbang 4 buah sampel lada dengan berat $\pm 0,5$ gram. Kedalam 3 buah sampel tadi ditambahkan piperin masing-masing sebesar 0,0063, 0,0085 dan 0,0101 gram. Sampel tanpa penambahan piperin serta ketiga sampel yang ditambahkan piperin tadi diekstraksi dalam labu didih menggunakan etanol pa sebagai pelarut dan pemanasan dilakukan selama 3 jam. Masingmasing hasil ekstraksi disaring dalam labu takar $100 \mathrm{ml}$ dan ditepatkan menggunakan pelarut etanol pa hingga tanda tera. Pipet $0,5 \mathrm{ml}$ larutan dari labu takar tadi, encerkan dalam labu takar 50 $\mathrm{ml}$ tepatkan hingga tanda tera.Cek absorbansi larutan pada panjang gelombang $343 \mathrm{~nm}$. Kadar piperin dihitung menggunakan rumus (1). Nilai perolehan kembali dihitung dengan rumus (Ambarwati, 2013) :

$$
\begin{aligned}
& \text { Akurasi }(\%)=\frac{\text { Nilai benar }- \text { nilai hitung }}{\text { Nilai benar }} \times 100 \% \\
& \text { Akurasi }(\%)=\frac{\text { A - B }}{\mathrm{C}} \times 100 \%
\end{aligned}
$$

$\mathrm{A}=\mathrm{Jumlah}$ piperin terukur $(\mathrm{g})$

$\mathrm{B}=$ Jumlah piperin pada sampel tanpa

penambahan analit $(\mathrm{g})$

$\mathrm{C}=$ Jumlah Piperin yang ditambahkan $(\mathrm{g})$

\section{Uji Linieritas}

Larutan standar 100 ppm dibuat dengan menimbang piperin murni sebanyak $0,01 \mathrm{~g}$ kemudian piperin dilarutkan menggunakan etanol pa hingga volume larutan tepat $100 \mathrm{ml}$. Uji linieritas dilakukan dengan membuat larutan piperin $1,2,4,6,8$ dan $10 \mathrm{ppm}$ dari larutan standar 100 ppm. Masing-masing diukur absorbansinya menggunakan spektrofotometer UV Vis pada panjang gelombang $343 \mathrm{~nm}$. Evaluasi uji linieritas dilakukan dengan menghitung koefisien determinasi (r) yang diperoleh dari analisis regresi linier (Cipac, 2003) dengan rumus :

$$
\begin{aligned}
\mathrm{y}= & \mathrm{ax}+\mathrm{b} \ldots \ldots \ldots \ldots \ldots . . .(6) \\
& \mathrm{a}=\text { slope } \\
& \mathrm{b}=\text { intercept } \\
& \mathrm{x}=\text { konsentrasi larutan piperin }(\mathrm{ppm}) \\
& \mathrm{y}=\text { absorbansi }
\end{aligned}
$$

\section{Batas Deteksi (LOD) dan Batas Kuantitasi (LOQ)}

Menurut Riyanto, 2014, untuk analisis yang menggunakan instrumen, batas deteksi dapat dihitung secara statistik menggunakan kurva kalibrasi. LOD dan LOQ dapat dinyatakan sebagai :

$$
\begin{gathered}
L O D=\frac{3 \times \mathrm{xb}}{\mathrm{Si}} \\
L O Q=\frac{10 \times \mathrm{Sb}}{\mathrm{Si}}
\end{gathered}
$$

$\mathrm{Sb}=$ simpangan baku

$\mathrm{Si}=$ slope kurva kalibrasi

\section{HASIL DAN PEMBAHASAN}

Penelitian ini memvalidasi metode pengujian piperin dalam lada hitam SNI 005:2013 yang dimodifikasi. Modifikasi yang dilaksanakan adalah dengan meringkas tahap pengenceran menjadi satu tahap pengenceran.

\section{Uji Presisi}

Presisi merupakan ukuran yang menunjukkan derajat kesesuaian antara hasil uji individual yang diukur melalui penyebaran hasil individual dari rata-rata (Riyanto, 2014). Penentuan presisi pada penelitian ini adalah mengukur repeatabilitas yaitu kedekatan hasil pengukuran dengan nilai sebenarnya melalui pengulangan pengujian sebanyak 7 kali, menggunakan alat, lokasi, kondisi serta personil yang sama dan dilaksanakan dalam interval waktu yang pendek. Hasil uji presisi tercantum pada Tabel 1.

Hasil pengujian didapat nilai persen simpangan baku relatif (\% RSD) dan CV Horwitz 
masing-masing 0,10123 dan 3,05145. Nilai $\%$ RSD $<2 \%$ menunjukkan metode pengujian piperin memiliki presisi yang baik (Riyanto, 2014). Hasil perhitungan didapat nilai CV Hitung sebesar 0,10123, nilai tersebut lebih kecil dari $2 / 3$ nilai CV Howitz yaitu 2,0343, hal ini menunjukkan metode pengujian memenuhi keberterimaan presisi analisis kimia (Ambarwati, 2013).

Tabel 1. Hasil Uji Presisi Piperin

\begin{tabular}{|c|c|c|c|c|}
\hline $\begin{array}{c}\text { Ulangan } \\
\text { Ke- }\end{array}$ & $\begin{array}{c}\text { Berat } \\
\text { Contoh } \\
\text { (g) }\end{array}$ & Abs & $\begin{array}{c}\text { Kadar } \\
\text { Air } \\
(\%) \\
\end{array}$ & $\begin{array}{c}\text { Kadar } \\
\text { Piperin } \\
(\%) \\
\end{array}$ \\
\hline 1 & 0.5020 & 0.687 & 8.58 & 6.0459 \\
\hline 2 & 0.5008 & 0.685 & 8.58 & 6.0427 \\
\hline 3 & 0.5001 & 0.683 & 8.58 & 6.0306 \\
\hline 4 & 0.5015 & 0.686 & 8.58 & 6.0431 \\
\hline 5 & 0.5011 & 0.685 & 8.58 & 6.0421 \\
\hline 6 & 0.5003 & 0.683 & 8.58 & 6.0311 \\
\hline 7 & 0.5014 & 0.686 & 8.58 & 6.0414 \\
\hline \multicolumn{4}{|c|}{ Simpangan $\mathrm{Baku}=$} & 0.00611 \\
\hline \multicolumn{4}{|c|}{ Rata-Rata $=$} & 6.03956 \\
\hline \multicolumn{4}{|c|}{$\% \mathrm{RSD}=\mathrm{CV}$ Hitung $=$} & 0.10123 \\
\hline & \multicolumn{3}{|c|}{ CV HOWITZ $=2^{(1-0,5 \log C)}=$} & 3.05145 \\
\hline
\end{tabular}

\section{Akurasi}

Akurasi merupakan ukuran kedekatan hasil analisis dengan kadar analit yang sebenarnya. Penentuan akurasi dilaksanakan dengan menambahkan analit yaitu piperin murni 99\% ke dalam sampel lada.Evaluasi akurasi dilakukan dengan menghitung nilai recovery. Nilai recovery merupakan rasio selisih kadar piperin dalam sampel yang ditambahkan analit dengan kadar piperin dalam sampel tanpa penambahan analit terhadap kadar analit yang ditambahkan ke dalam sampel. Piperin murni yang ditambahkan ke dalam sampel masingmasing sebesar 0,0101, 0,0063 dan 0,0085 gram.

Nilai recovery yang diperoleh berkisar antara 98,88-101,87\%, hal ini menunjukkan metode analisis dapat memberikan hasil yang mendekati dengan nilai sebenarnya. Batas keberterimaan nilai recovery untuk kadar analit dalam matrik sampel kurang dari $10 \%$ adalah $97-$ 103\% (Cipac, 2003 dan Riyanto, 2014). Hal tersebut ditunjukan seperti pada tabel 2 .
Tabel 2. Nilai Recovery Piperin

\begin{tabular}{|c|c|c|c|}
\hline No & Sampel Uji & $\begin{array}{l}\text { Piperin } \\
\text { terukur } \\
\text { (gr) }\end{array}$ & $\begin{array}{c}\text { Recovery } \\
(\%)\end{array}$ \\
\hline 1 & $\begin{array}{l}\text { Sampel tanpa } \\
\text { penambahan } \\
\text { piperin }\end{array}$ & 0.0302 & - \\
\hline 2 & $\begin{array}{c}\text { Sampel + 0,0101 } \\
\text { gram piperin } \\
\text { murni }\end{array}$ & 0.0405 & 101.77 \\
\hline 3 & $\begin{array}{c}\text { Sampel }+0,0063 \\
\text { gram piperin } \\
\text { murni }\end{array}$ & 0.0364 & 98.88 \\
\hline 4 & $\begin{array}{c}\text { Sampel }+0,0085 \\
\text { gram piperin } \\
\text { murni }\end{array}$ & 0.0390 & 101,87 \\
\hline
\end{tabular}

\section{Linieritas}

Linieritas merupakan ukuran kemampuan metode analisis memberikan respon yang proporsional terhadap konsentrasi analit dalam sampel (Riyanto, 2014). Hasil pengujian linieritas diperoleh sebagaimana Tabel 3. Dalam bentuk kurva linier respon kadar piperin terhadap absorbansi tertera pada gambar 1 .

Tabel 3. Hasil Linieritas Piperin

\begin{tabular}{ccc}
\hline No & $\begin{array}{c}\text { Larutan Piperin } \\
\text { (ppm) }\end{array}$ & Absorbansi \\
\hline 1 & 1 & 0.083 \\
2 & 2 & 0.158 \\
3 & 4 & 0.329 \\
4 & 6 & 0.519 \\
5 & 8 & 0.685 \\
6 & 10 & 0.874 \\
\hline
\end{tabular}

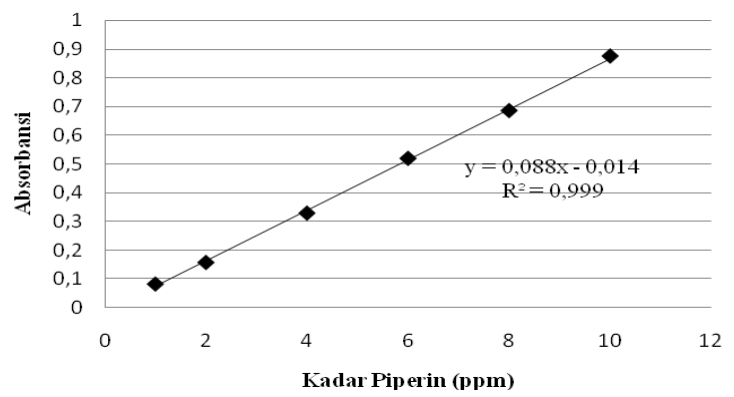

Gambar 1. Kurva Linieritas Piperin

Berdasarkan gambar 1, hubungan antara kadar piperin (ppm) terhadap absorban dapat dinyatakan dalam persamaan linier $\mathrm{y}=0,088 \mathrm{x}$ 0,014 . Nilai $-0,014$ pada persamaan kuva linieritas menunjukkan kepekaan analisis terutama 
instrumen yang digunakan. Nilai koefisien determinasi kurva linieritas adalah sebesar 0,999, hal ini memenuhi syarat keberterimaan validasi yaitu >0,99 (Cipac, 2003 dan Riyanto, 2014).

\section{Batas Deteksi dan Batas Kuantitasi}

Penentuan nilai batas deteksi yang dilakukan merupakan penentuan batas deteksi instrumen, yang mencakup batas deteksi (LOD) dan batas kunatitasi (LOQ). Penentuan LOD dan LOQ dilaksanakan berdasarkan data kurva linieritas piperin (Riyanto, 2014). Data perhitungan LOD dan LOQ tertera pada Tabel 4.

Tabel 4. Penentuan Nilai LOQ dan LOD

\begin{tabular}{|c|c|c|c|c|}
\hline $\begin{array}{c}\text { Piperin } \\
\text { (ppm) }\end{array}$ & Abs & yc & yi-yc & $(y i-y c)^{2}$ \\
\hline 0 & 0 & -0.014 & 0.014 & 0.000196 \\
\hline 1 & 0.083 & 0.074 & 0.009 & $8.1 \mathrm{E}-05$ \\
\hline 2 & 0.158 & 0.162 & -0.004 & $1.6 \mathrm{E}-05$ \\
\hline 4 & 0.329 & 0.338 & -0.009 & 8.1E-05 \\
\hline 6 & 0.519 & 0.514 & 0.005 & 0.000025 \\
\hline 8 & 0.685 & 0.69 & -0.005 & $2.5 \mathrm{E}-05$ \\
\hline 10 & 0.874 & 0.866 & 0.008 & $6.4 \mathrm{E}-05$ \\
\hline \multicolumn{4}{|c|}{ SD RESIDUAL } & $\begin{array}{c}6.20745 \mathrm{E}- \\
05\end{array}$ \\
\hline \multicolumn{4}{|c|}{ LOD } & 0.002116 \\
\hline \multicolumn{4}{|c|}{ LOQ } & 0.007054 \\
\hline
\end{tabular}

Hasil perhitungan menunjukkan nilai LOD dan LOQ masing-masing 0,002116 dan $0,007054 \mathrm{ppm}$. Nilai LOD bermakna konsentrasi piperin terendah yang masih dapat terdeteksi adalah 0,002116 ppm. Nilai LOQ sebesar 0,007054 ppm bermakna nilai tersebut merupakan konsentrasi terendah yang masih dapat terdeteksi oleh spektrofotometer dengan tingkat presisi dan akurasi yang dapat diterima (Riyanto, 2014).

\section{KESIMPULAN}

Validasi terhadap metode analisis piperin berdasarkan SNI lada hitam tahun 2013 yang dimodifikasi, memiliki nilai \% RSD, CV Horwitz, rentang nilai perolehan kembali dan koefisien determinasi kurva linieritas masing-masing sebesar 0,$10123 ; \quad 3,05 ; 98,88-101,87 \%$ dan 0,999 . Nilai LOD dan LOQ yang diperoleh masing-masing sebesar 0,002116 dan 0,007054 ppm. Nilai parameter validasi yaitu presisi, akurasi dan linieritas memenuhi batas keberterimaan analisis kimia kuantitatif, sehingga metode analisis piperin yang dimodifikasi ini dapat digunakan sebagaimana peruntukkannya yaitu untuk pengujian piperin dalam lada hitam.

\section{DAFTAR PUSTAKA}

Leila Gorgani, MaedehMohamadi, Ghasem D Najafpour, (2017), Piperin-The Bioactive Compound of Black Pepper : From Isolation to Medical Formulations, Comprehensive Reviews in Food Science and Food Safety, Vol. 16.

Gupta Vishvnath, Jain U.K.,( 2011), Quantitative Analysis of Piperin in Ayuverdic Formulaation by UV Spectrophotometry, International Journal of Pharma Science and Research, Vol. 2.

Anwar Hadi (2018), Persyaratan Umum Kompetensi Laboratorium Pengujian dan Laboratorium Kalibrasi ISO/IEC 17025 : 2017, Gramedia.

Nining Sugihartini, Achmad Fudholi, SuwidjiyoPramono, Sismindari (2014), Validasi Metode Analisa Penetapan Kadar Epigalokatekin Galat dengan Kromatografi Cair Kinerja Tinggi, Pharmaciana, Vol. 4, Nomor 2.

Anonim, How to Meet ISO 17025 Requirements for Method Verification. from http://www.aoac.org/al acc_guide_2008.pdf

Guidelines on Method Validation to be Performed in Support of Analytical Methods for Agrochemical Formulations, 2003, Cipac.org.

Riyanto Ph.D (2014), Validasi dan Verifikasi Metode Uji Sesuai dengan ISO/IEC 17025 Laboratorium Pengujian dan Kalibasi, Deepublish, 2014.

Ambarwati, Novida Ariyani, Maria Fatima Palupi (2013), Validasi Metoda Spektrofotometri pada Uji Kadar Sediaan Injeksi Obat Hewan Enrofloksasin, Sain Veteriner 31(2).

Lampung Directory, Dinas Perdagangan Provinsi Lampung, 2018

Nerdy, 2017, Validation of Ultraviolet Spectrophotometry Met hod For Determination of Mefenamic Acid Level in Suspension Dosage Forms, Jurnal Natural, Volume 17(1).

Ridho Asra, Harrizul Rivai, Widya Astuti, Pengembangan dan Validasi Metode Analisis Betametason Tablet dengan Metode 
Absorbansi dan Luas Daerah di Bawah Kurva Secara Spektrofotometri Ultraviolet.
R.A Day Jr, A.L. Underwood, Analisa Kimia Kuantitatif, Penebit Erlangga, Cetakan kedua, 1988. 